\title{
Exploration and Study of Applied Undergraduate Math Teaching based on Mathematical Modeling Ideas*
}

\author{
Zhiyang LIU' ${ }^{1}$, Shijian $\mathrm{LI}^{2}$
}

Guangdong University of Science \& Technology, Dongguan, Guangdong, P. R. C. (hsp0121@126.com)

\begin{abstract}
Based on the problems existing on teaching materials, students, teachers and teaching methods of applied undergraduate math teaching, the study proposed to integrate the mathematical modeling ideas into the applied undergraduate teaching, so as to solve the problems existing on teaching materials, students, teachers and teaching methods, expire students' interests of learning and abilities of solving practical problems by theoretical knowledge, and meet the applied undergraduate institutions' demand for talent cultivation.
\end{abstract}

Keywords — applied undergraduate education, mathematical modeling, teaching research, applied abilities.

\section{基于数学建模思想的应用型本科数学教学探索与研究}

\author{
刘志扬 $^{1}$ 李世建 $^{2}$ \\ 广东科技学院, 东莞, 广东, 中国
}

摘 要 文章从应用型本科数学教学中教材、学生、教师和教法四方面存在的问题出发, 提出将数学建模思想渗透到应用型本科 数学教学中, 解决教学中教材、学生、教师和教法四方面存在的问题, 激发学生学习数学兴趣的同时培养学生用理论知识解决实际 问题的能力, 以达到应用型本科院校对人才培养的要求。

关键词 应用型本科教育, 数学建模, 教学研究, 应用能力

\section{1. 引言}

应用型本科教育主要面向企业, 培养从事实践性、操 作性较强的工作, 在生产与经营管理一线解决实际问题的 应用型技术人才, 以 “应用” 为主旨和特征构建课程和教 学内容体系, 与普通高等教育有着本质的区别。传统的本 科主要是培养研究型高级人才, 强调基础理论研究和技术 开发; 高职高专培养操作型人才, 强调技术操作; 而应用 型本科主要培养应用型人才, 强调应用理论研究和技术应 用。

数学模型作为一种数学方法, 是为了某个特定的研究 目的, 在做出一些必要的简化假设下, 运用形式化的数学 语言, 去抽象地、概括地表达所研究对象的一种数学结构。 它或者能解释特定现象的现实性态, 或者能预测对象的未 来性态, 或者能提供处理对象的最优决策或控制。数学建
模就是建立数学模型, 解决实际问题的过程。通过对实际 问题的调查与思考, 研究分析出其固有的特征和内在规律, 提出必要的假设, 建立起反映实际问题的数学模型, 求出 该模型的解并应用于类似普遍的实际问题中。

数学作为应用型本科专业非常重要的基础课程, 在教 学中应该传授学生数学知识的同时让学生掌握数学的思想 方法、形成数学应用思维。为适应 “以知识为基础、以能 力为重点、以服务为宗旨, 注重知识、能力、素质协调发 展, 学习、实践和职业技术能力相结合” 的应用型本科教 育的人才培养模式, 应用型本科数学教学可以结合数学建 模思想, 激发学生学习数学兴趣的同时培养学生的数学应 用意识, 做到学以致用。

*广东省教育厅、财政厅立项资助项目（资助号：2013WYXM0136） 


\section{2. 应用型本科数学教学中存在的问题}

2.1 教材方面: 内容陈旧, 太注重逻辑理论, 少关注实际应 用

应用型本科数学课程主要有高等数学、线性代数和概 率论与数理统计, 教材内容基本上沿用传统的知识体系, 或者是将原有本科数学教学内容进行压缩, 内容陈旧并且 一味地追求理论的完整性, 没有考虑 “必需、够用” 的原 则。教材使用较多的定义和定理, 没有将现代的数学思想、 数学观念和数学方法融入其中, 只注重严密的逻辑推导, 忽略它们产生的背景与沸源, 学生在学习过程中就很难真 正理解这些概念, 更谈不上进行实际应用。

2.2 学生方面: 基础较差, 缺乏兴趣, 学习效率低下

随着高校招生规模的扩大, 民办应用型本科院校入学门 槛一度降低, 新生数学基础较差, 很难适应应用型本科数 学课程的学习。大部分学生学习数学只是为了应付考试, 对数学中的定理和公式采取死记硬背, 知其然而不知其所 以然; 少数学生对数学毫无兴趣, 加上没有良好的学习习 惯, 上课开小差、睡觉、玩手机现象时有发生。以上现象 导致的结果是: 学生在数学课程学习中学不到数学的思维 与方法, 无法达到应用型本科人才的要求。

2.3 教师方面: 观念落后, 对培养应用型人才的引导意识不 够

应用型本科教育是以培养应用型人才为导向的教育, 要求教师了解服务于生产、经营、管理和服务一线的实际 情况, 在数学课程教学中有针对性地将数学教学与学生所 学专业、就业岗位紧密联系在一起, 以达到用所学数学知 识解决实际问题的目的。然而在实际教学中, 教师这方面 的观念非常落后, 对应用型本科数学课程教学目标把握不 清楚, 无法对教学内容做出适当的调整, 加上对学生所学 专业课程内容的不了解, 在数学教学中按照自己在数学专 业学到的知识与方法进行讲解, 忽略数学概念的产生背景 和数学知识的实际应用, 难以培养学生用数学知识解决实 际问题的意识, 难以提升学生可持续发展的应用能力和创 新精神。

\section{4 教法方面: 模式单一, 学生参与度低, 教与学脱节}

应用型本科数学教学本应该体现其实践性, 但很多教 师仍然停留在以教师为中心、以知识讲解为主的教学模式 中, 课堂上教师口若悬河地讲解那些抽象的数学理论, 忽
视这些数学理论的来龙去脉与实际应用, 课堂缺乏实践性、 趣味性和学生主体性。陈旧、单一的教学方法加上很少使 用现代化的辅助教学手段, 使得教师的 “教”与学生的 “学” 严重脱节, 学生参与度低, 教学效果不言而喻。。

\section{3. 将数学建模思想融入应用型本科数学教学的探索 与研究}

数学既来源于生活又应用于生活, 现实生活中的许多 实际问题与数学知识息息相关。在应用型本科数学课堂教 学中, 如果教师能结合数学建模思想将教学内容与现实生 活紧密联系, 将生活中的问题用数学知识建立对应的数学 模型, 并用此模型来解决实际工作中类似的普遍问题, 把 生活问题数学化, 使数学价值最大化, 学生对数学的认识 与兴趣便会提升, 学生分析问题、解决问题的能力也会得 到大大提高, 教学效果就会有质的突破。下面主要从四个 角度谈谈将数学建模思想融入应用型本科数学教学的探索 与研究:

3.1 用数学建模思想处理教材内容, 建立数学知识与现实生 活的联系

应用型本科数学课程教材中有许多内容与实际问题紧密 相连, 教师处理教材内容时, 在保证完成基本教学计划的 前提下可以适当增减教学内容, 将那些理论性强而应用价 值不高的内容可以删去, 对那些应用价值高的内容重点讲 解并适当扩充, 尽量用数学建模思想建立数学知识与实际 问题的联系。如: 在《高等数学》教材内容处理时, 将第 二重要极限与复利、连续复利及贴现建立联系, 将导数的 概念与经济学中的边际与弹性建立联系, 将一阶常系数线 性非齐次微分方程与市场上的商品价格波动建立联系等。 在《线性代数》教材内容处理时, 将矩阵与循环比赛名次 的确定建立联系, 将线性方程组求解与交通流量问题建立 联系, 将线性规划问题与最优生产计划建立联系等。在《概 率论与数理统计》教材内容处理时, 将概率乘法公式及全 概率公式与抓阄公平问题建立联系, 将贝叶斯公式与实际 问题中如何追究责任建立联系, 将二项分布、中心极限定 理及正态分布的近似计算与人寿保险问题建立联系等。

3.2 用数学建模思想培养学生的数学应用意识, 激发学生学 习数学的兴趣

在对部分应用型本科学生进行调查和座谈时发现，他们 认为数学是一门枯燥无味、毫无用处的课程, 对数学的学 习没有兴趣而是很大程度迫于考试。究其原因, 是因为教 
师在教学过程中只是按照课本理论进行机械讲解, 学生不 能深刻理解数学公式、定理的含义, 不能将这些理论在实 践中灵活应用, 无法感受到数学的价值。如果教师在教学 中结合数学建模思想培养学生的数学应用意识, 效果便会 得到改观, 因为数学建模能使实际问题直观的展现在学生 面前, 在分析处理问题时, 学生可以将抽象的数学知识与 实际问题建立联系, 更快、更准确地理解数学符号的含义, 从而能创造性地解决实际问题。因此, 数学建模能最大限 度地体现数学的应用价值, 学生能在数学建模过程中体会 数学的鬼米力, 感受到数学有用的同时激发出对数学的兴趣。

3.3 借助数学建模思想提升教师自身综合素质, 实现对学生 的正确引导

应用型本科院校教师素质的高低直接决定教学质量的好 坏, 教学质量的好坏是所培养学生能否成才的关键。要搞 好应用型本科数学的教学, 教师不仅要有扎实的专业数学 知识, 还要有用数学知识解决实际问题的能力, 但应用型 本科数学教师在大学期间接受的都是传统的数学教育, 依 据他们现有的教育观念和知识结构, 很难真正实现数学知 识与实际问题的对接。为达到这些要求, 应用型本科数学 教师应该敢于更新观念, 在教学中借助数学建模思想重新 学习, 提升自身的数学建模能力的同时实现对学生的正确 引导。

3.4 结合数学建模思想采用任务驱动法进行课堂教学, 提高 学生的参与度

应用型本科数学教学过程中, 由于教学模式单一、教 学方法传统, 学生学习数学的兴趣不大, 参与度低, 教师 的 “教” 与学生的 “学” 脱节。为了解决这些问题, 教师 可以结合数学建模思想采用任务驱动法进行课堂教学: 对 每次课的教学内容设置一项任务或提出一个问题, 该任务 与生活中的实际问题息息相关, 要求学生对相关数学知识 的学习, 灵活运用这些数学知识建立相应的数学模型, 并 用此模型来完成教师所设置的任务。学生在完成教师设置 的任务过程中, 可以采用分组合作、集体讨论、课堂学习 与课后查阅资料的方式积极主动参与任务的完成, 从而达 到以 “任务” 驱动学生参与学习的目的, 不但学生的创造 性思维得到激发, 学生的实践动手能力还会得到加强。比 如: 在讲授正态分布时, 教师可以结合正态分布设置一项 任务, 让学生通过对相关知识点的学习, 灵活运用相关知 识来完成所设置的任务。

任务: 某高校计划招收全日制硕士研究生 300 名, 其中 前 40 名为公费生, 自费生 260 名。报考人数 1657 人, 考试
满分 400 分, 考后得知, 考试平均成绩为 166 分, 360 分以 上的高分考生 31 人。小强在这次考试中得 346 分, 请问他 能否被录取？能否成为公费生？

解析：该问题是学生本科毕业考研时非常关心的问 题, 可以用正态分布来估算录取分数线及考生名次。由于 有 1657 人参加考试, 可以认为考试成绩 $X$ 服从正态分布, 且平均分 $\mu=166$ 分, 即 $X \sim N\left(166, \sigma^{2}\right)$ 。因为 360 分以 上人数为 31 人, 则

$P\{X>360\}=P\left\{\frac{X-166}{\sigma}>\frac{360-166}{\sigma}\right\}=1-\Phi\left(\frac{194}{\sigma}\right)=\frac{31}{1657}=0.019$ 从而 $\Phi\left(\frac{194}{\sigma}\right)=0.981$, 查表得 $\frac{194}{\sigma}=2.08$, 即 $\sigma \approx 93$ 。 所以 $X \sim N\left(166,93^{2}\right)$, 且有

$P\{X>346\}=P\left\{\frac{X-166}{93}>\frac{346-166}{93}\right\}=1-\Phi(1.94)=1-0.974=0.026$ 在所有考生中，高于小强成绩的人约有

$1657 \times 0.026=43$ 人, 因此小强的名次大约是 44 名, 在 40 名之后 300 名之前, 他能被录取但不能成为公费生。

\section{4. 结论}

随着我国经济的迅速发展, 市场对高级应用型人才的 需求日益增加, 应用型本科院校越来越注重对学生应用能 力的培养。理论与实践证明, 在应用型本科数学教学中, 教师结合数学建模思想研究教材、学生和教学方法, 不但 可以有效地解决应用型本科数学教学中存在的问题, 还能 培养学生用数学知识解决实际问题的能力, 以达到应用型 本科院校对人才培养的要求。

\section{参考文献(References)}

[1] Duan Yong, "Application of Mathematical Modeling Ideas in College Math Teaching", China University Teaching, vol.10, 2007.

[2] Yang Guiyuan, Practice of Mathematical Model Application, Hefei: Hefei Technical University Press, 2007.

[3] Chen Dongyan, Li Dongmei and Wang Shuzhong. Mathematical Modeling, Beijin: Science Press, 2007.

[4] Bi Xiaohua and XuJun, "Initial Exploration of Integrating Mathematical Modeling Ideas into Applied Undergraduate Math Teaching", Education and Vocation, vol. 9, 2011. 
[5] Wang Peng, "Exploration of the Usage of Mathematical Modeling Teaching in Applied Undergraduate Talent Cultivation", Success, vol. 11, 2011.

[6] ZhouGang, "Exploration of Math Course Teaching of Technology Application-Oriented Undergraduate Institutions”, China Education Innovation Herald, vol.2, 2009.

[7] Hong Yongchen and Li Xiaobin, "Better Mathematical Modeling Teaching to Improve Students' Quality", Journal of
Shanghai Finance University, vol.3, 2004.

[8] Li Daqian, "Integrating the Mathematical Modeling Idea into Mathematics Class Main Courses”, China University Teaching, vol.1, 2006.

[9] Xiong Wenting, Tao Longfeng and WangMin, "The Methods of Mathematical Modeling Integrating into Higher Mathematical Teaching at Applied Undergraduate Institutions”, Science and Engineering, vol.12, 2012. 